\title{
ARSITEKTUR ENTERPRISE SISTEM INFORMASI CENTRALIZED TRAFFIC CONTROL (CTC) KERETA API
}

\author{
Debora ERP ${ }^{1}$, Yudhistira Sulaeman ${ }^{2}$, Nur Achadi ${ }^{3}$ \\ Jurusan Sistem Informasi Bisnis \\ Program Pasca Sarjana Magister Sistem Informasi \\ Sekolah Tinggi Manajemen Informatika dan Komputer LIKMI \\ Jln. Ir. Juanda No.96 Bandung, Indonesia
}

\begin{abstract}
This research have a purpose to analyze and provide the design of CTC Information system in railway transportation (train), which use EAP (Enterprise Architecture Planning) method, in order to maximize the use of CTC which emphasize on digital business. In this case, Digital business, rail way in a small station is integrated to a system supporting CTC which could help the rail-driver in their job. The center of railway transport also could effectively control all of the transport and use of rail in the small stations. Keywords: Enterprise Architecture Planning, Centralized Traffic Control, Stasiun Kereta Api
\end{abstract}

\section{PENDAHULUAN}

Kereta api merupakan moda angkutan massal yang memiliki banyak kelebihan dari modal angkutan lain terutama sebagai solusi dari masalah kemacetan yang terjadi di tanah air. Kenyamanan dalam perjalanan yang bebas macet membuat banyak masyarakat menggunakan moda transportasi ini sebagai alat transportasi mereka. Semakin meningkatnya jumlah sarana kereta api membuat lalu lintas perjalanan kereta api juga menjadi semakin padat sementara peningkatan jumlah jalur cenderung tetap sehingga sering membuat kereta api harus saling menunggu giliran memakai jalur sesuai dengan perintah yang diberikan pengatur perjalanan kereta api dari stasiun karena beberapa kereta api itu akan melewati jalur yang sama. Kereta api hanya berjalan di atas rel sehingga tidak mungkin menghindar bila ada halangan di atas jalur, oleh karenanya sistem harus benar-benar dapat menjaga agar jangan sampai ada lebih dari 1 kereta api yang berada pada jalur yang sama. Komunikasi antara petugas di stasiun dengan petugas di atas kereta api hanya menggunakan komunikasi radio sehingga tidak ada visualisasi tentang posisi kereta api secara pasti. Tidak adanya sistem peringatan dini jika ada kemungkinan tabrakan antara kereta api, kereta api hanya dapat berjalan di atas rel dan tidak bisa melakukan pengereman mendadak.

Kondisi CTC di Jawa : Cirebon membawahi 8 stasion, Purwokerto membawahi 27 stasion, Yogyakarta membawahi 8 stasion, Tasikmalaya membawahi 7 stasion. Penelitian ini diujicobakan pada jalur kereta api Tasikmalaya - Banjar dengan kereta api yang melintas seperti jurusan Bandung Surabaya (Mutiara Selata, Argo Mulia). Dengan kondisi ini, trafick posisi kereta api di setiap stasion dapat divisualisasikan di layar komputer.

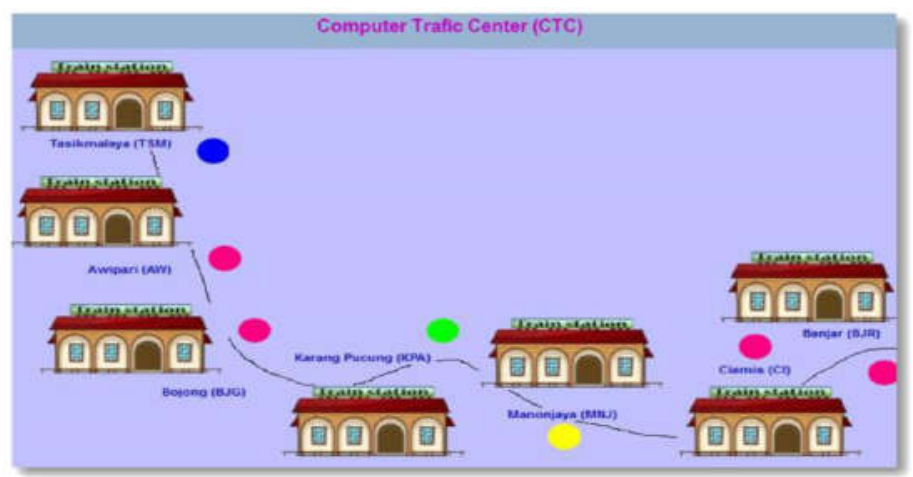

Gambar 1. Stasion di bawah Tasikmalaya 
Stasion pusat dipasang di Tasikmalaya yang akan memonitor stasion-stasion (7 station) sebagai berikut Tasikmalaya (TSM), Awipari (AW), Manonjaya (MNJ), Ciamis (CI), Bojong (BJG), Karang Pucung (KPA), Banjar (BJR)

\section{METODOLOGI PENELITIAN}

Adapun metodologi pengembangan dari Sistem yang akan dibangun adalah sebagai berikut

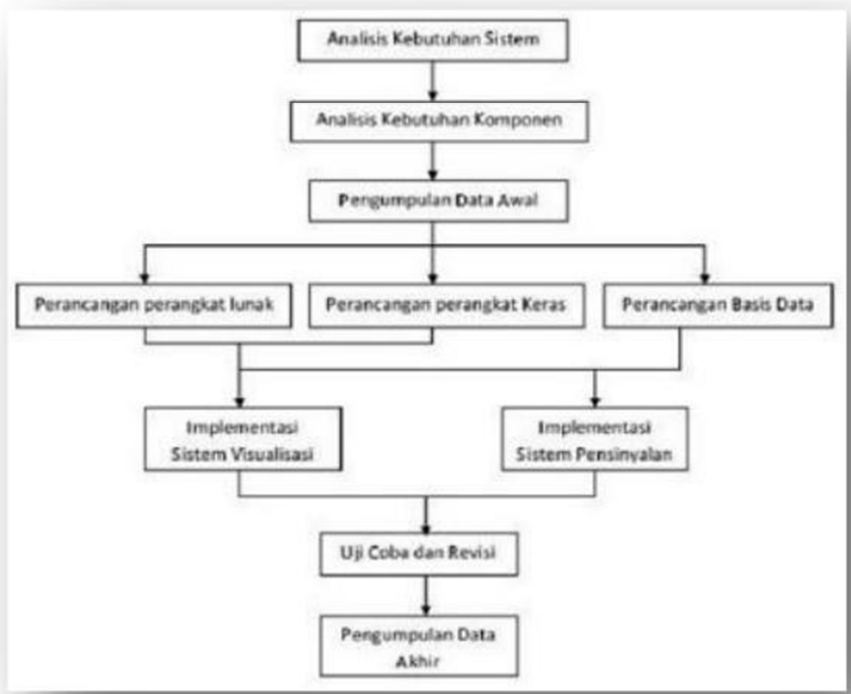

Gambar 2. Metodologi Pengembangan

Adapun Sistem Arsitektur yang akan dibangun adalah sebagai berikut

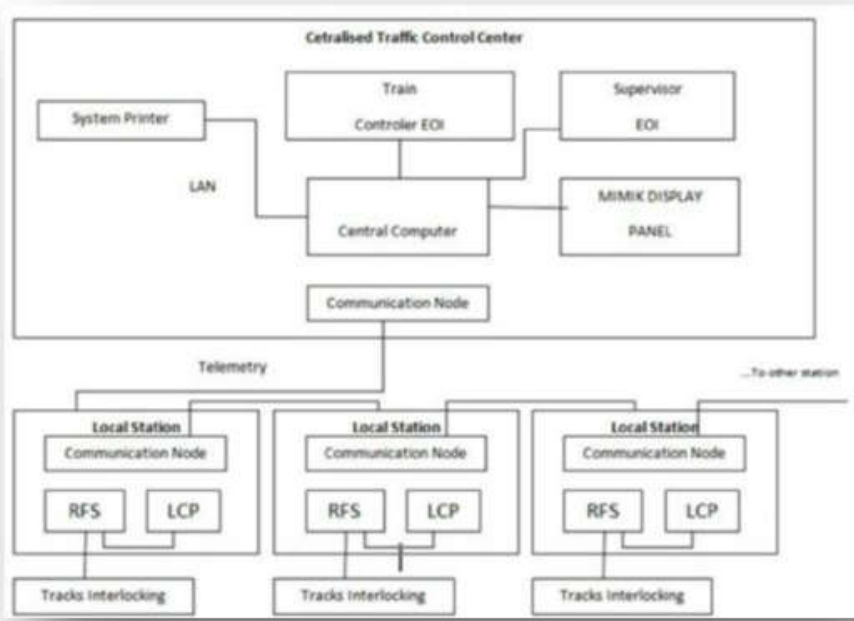

\section{Gambar 3. Sistem Arsitektur}




\section{HASIL DAN PEMBAHASAN}

Contoh kasus yang akan dibuat adalah di sebuah stasion remote Awipari dan dimonitor serta dikendalikan di stasion pusat (NOC) tasikmalaya, akan ditampilkan display seperti gambar di bawah ini.

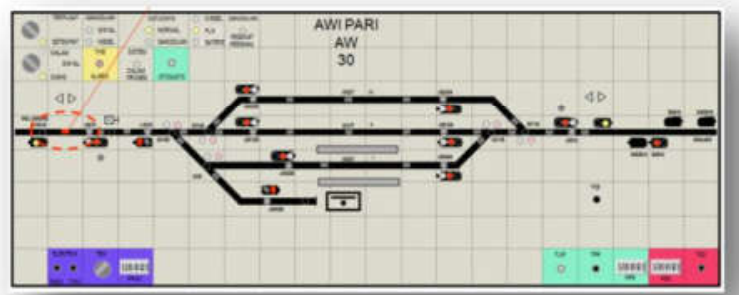

Gambar 4. Contoh Kasus

Gambar kondisi ruang NOC sebagai berikut :

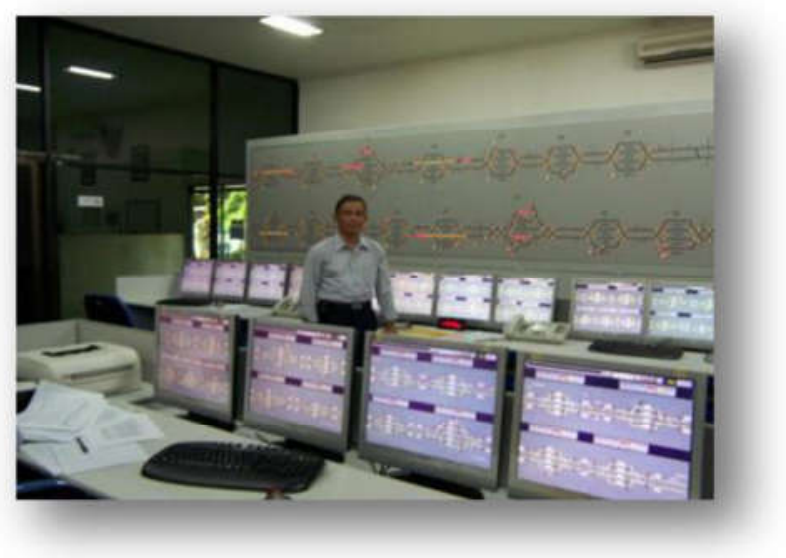

Gambar 5. Kondisi Ruang

\section{KESIMPULAN}

Dengan tampilan mimic display di NOC dapat memberikan kemudahan dalam melakukan pengawasan terhadap perjalanan kereta api secara keseluruhan. Dengan fitur kendali remote dan lokal operator dapat menjalankan tugasnya dalam segala situasi. Perjalanan kereta api selalu tersimpan ke dalam database sehingga memudahkan dalam melakukan maintenance ataupun investigasi terhadap kereta api tersebut.

\section{DAFTAR PUSTAKA}

Westinghouse, "Brake and Signal System”, Document Manual

Yudi Yuliyus, "SISTEM KEAMANAN KERETA API DENGAN MENGGUNAKAN GPS SEBAGAI PEMANTAU JALUR DAN POSISI SARANA", Prosiding InsiNas 2012

Fasilitas Pengoperasian KA,Balai Pelatihan Operasi dan Pemasaran, 2013

Automatic Signalling System for Trains, Kota Shiva Kumar, Suresh Angadi,international Journal of Engineering Trends and Technology(IJETT)-Volume 4-April 2013 ISSN: 2231

Hazard Identificaiton of Railway Signaling System Using PHA and HAZOP Methods,Jong-Gyu Hwang, Hyun-Jeong Jo2,International Journal of Automation and Power Engineering (IJAPE) Volume 2 Issue 2, February 2013 